\title{
Mujeres y niñas entre hilos: condiciones de trabajo en la industria textil a principios del siglo XX. Una experiencia de clase generizada
}

( Verónica Norando

CONICET-IIEGE/UBA

Fecha de recepción: 20 de febrero de 2018. Fecha de aceptación: 1ํ de diciembre de 2018.

\section{Resumen}

En este trabajo se abordan las experiencias de las trabajadoras textiles de principios del siglo XX, haciendo especial énfasis en las obreras de Gratry, ya que estas trabajadoras fueron protagonistas del ascenso huelguístico de 1910. En el estudio de su trabajo y organización, tratamos de identificar los mecanismos de explotación específicos de la mujer trabajadora, visibilizando las condiciones de trabajo y las diferencias de género de su experiencia situada en la fábrica textil del sur de la ciudad de Buenos Aires, en el barrio obrero de Pompeya. Guía esta investigación la idea en torno al patriarcado y el capitalismo como un solo sistema que explota a hombres y mujeres de manera específica, es decir en tanto tales, y la búsqueda de sus mecanismos subyacentes. Nuestra hipótesis es que la especificidad de la explotación de las mujeres de la industria textil de Buenos Aires está determinada por el carácter de su fuerza de trabajo, que es totalmente distinto al masculino, porque las mujeres cumplen una jornada laboral diferente, que incluye el trabajo doméstico y de ahí su especificidad y la mayor cantidad de plusvalía extraída. Este trabajo es el resultado original del examen de un cuerpo variado de fuentes obreras y oficiales. Nuestra metodología es el materialismo dialéctico y hemos hecho un examen cuali-cuantitativo de las fuentes, en particular del Boletin del Departamento Nacional del Trabajo.

Palabras clave:

Relaciones de género, condiciones de trabajo, industria textil, formas de explotación, trabajo femenino, trabajo infantil/niñas.

\begin{abstract}
This paper addresses the experiences of textile women workers of the early twentieth century, with special emphasis on the women workers of Gratry, because theywere the protagonists of the 1910 strike rise. In the study of their work and organization, we try to identify the specific exploitation mechanisms of the woman worker, making visible the working conditions, and the gender differences of their experience located in the
\end{abstract}


textile factory in the south of the city of Buenos Aires, in the working-class neighborhood of Pompeya. This research is guided by the idea ofpatriarchy and capitalism as one system that exploits men and women as such in a specific way. It seeks to find its underlying mechanisms. Our hypothesis is that the specificity of the exploitation of women in the textile industry of Buenos Aires is determined by the nature of their labor force, which is totally different from the male one because it makes a different working day, which includes domestic work and hence its specificity and the greater amount of surplus value extracted. This work is the original result of the examination of a varied body of workers documents and official sources, our methodology is dialectical materialism and we have made a qualitative-quantitative examination of the sources, in particular of the Boletín del Departamento Nacional del Trabajo.

Keywords:

Gender relations, working conditions, textile industry, forms of exploitation, women work, child labor/little girls.

\section{Introducción ${ }^{1}$}

Aquí analizo las experiencias de las trabajadoras de la industria textil de principios del siglo XX en su ámbito laboral. Las preguntas principales que guían esta investigación se refieren a la explotación específica de las mujeres y a cuál es su mecanismo de extracción de plusvalor. Gracias a la observación y análisis de sus condiciones de trabajo llego a la respuesta. La hipótesis de trabajo es que las mujeres de la clase obrera tienen una jornada laboral específica cuya característica particular es que incluye el trabajo doméstico y esto es lo que marca la especificidad de su fuerza de trabajo. Estas particularidades de la explotación de las mujeres de la clase trabajadora las hacen pasibles de un tipo especial de explotación: la explotación específica de la mujer.

A nivel teórico-conceptual, este estudio se realiza desde una perspectiva que reconoce a la sociedad contemporánea regida por el modo de producción capitalista patriarcal (Norando, 2018 b, e/p) por lo tanto considero el estudio de la clase obrera y sus experiencias desde un punto de vista sexuado, ya que el patriarcado y el capitalismo forman parte de un mismo sistema que explota tanto a las mujeres como a los hombres en tanto tales, es decir, como miembros de clases sexuadas, a las que denomino generizadas (Norando, 2020, , 2018 a y b). A nivel metodológico utilizo el materialismo dialéctico como praxis para llevar adelante mis análisis de la realidad histórica sobre las trabajadoras textiles de principios del siglo XX. Me he explayado extensamente a nivel metodológico sobre esta forma de abordaje en otras obras (Norando, 2020 y 2018 a, b y e/p).

Este trabajo se nutre de viejas y nuevas tradiciones provenientes del marxismo y del feminismo, tanto radical como socialista. En cuanto a los debates más viejos, han ahondado y discutido sobre las relaciones entre capitalismo y patriarcado y entre el trabajo doméstico y el capitalismo (Benston, 1969; Delphy, 1977; Artous, 1982). Este debate no pudo tener su correlato en la Argentina hasta la década de 1980 cuando, haciéndose eco de estas discusiones, surgieron los trabajos pioneros de Mabel Bellucci y Cristina Camusso que integraban las relaciones de clase y de género ${ }^{2}$ como un correlato de los debates sobre el trabajo doméstico. Aun así, fueron trabajos aislados. Otros estudios comenzaban a reparar en las experiencias de las mujeres en el ámbito laboral al abordar la relación clase-género.

1 Quiero expresar un gran agradecimiento por los comentarios y sugerencias recibidos en la elaboración de este trabajo a Andrea Andújar y a Dora Barrancos.

2 Dora Barrancos ofició como directora del Proyecto de Bellucci y Camusso, "Articulación de clase y género en las luchas de las mujeres anarquistas”, Conicet, 1987-1989. Ver también Bellucci y Camusso (1987) y Bellucci (1992). 
Estos debates se sucedieron paralelamente a que el marxismo se renovaba y avanzaba en dejar atrás determinismos vulgares de raigambre estalinista. Es así como en la Argentina comenzaron a surgir trabajos que ahondaron sobre las experiencias de los/ as trabajadores desde una perspectiva de género relacionados con distintos aspectos como la cultura de izquierda, la relación con el Estado, el mercado de trabajo, etc. (Barrancos, 1990; Feijóo, 1990; Lobato, 1993, 2001). Este examen dialoga con ya clásicos estudios que han incluido la categoría de género en el mundo del trabajo (Lobato, 2001, 2007a). Retomo estas líneas desde la historia social del trabajo con perspectiva de género. En la Argentina, estamos llamando la atención sobre la pertinencia y la potencia de la inclusión de las categorías de clase, género, etnia y generación y de su relación en el accionar político de los trabajadores, así como también se está focalizando sobre la utilización del concepto de género para el análisis de la constitución de identidades obreras (Norando, 2011; Margarucci, 2015) y para el análisis de la cotidianeidad y la sociabilidad en el mundo del trabajo (; D'Uva y Palermo, 2015; Norando, 2019b e/p; Allemandi, 2017). También se están realizando trabajos que ponen en juego la relación de la sexualidad en la constitución de identidades obreras y en el activismo político de los trabajadores (Andújar, 2015, 2016; Trebisacce y Mangiantini, 2015; Scheinkman, 2015; Norando, 2020). Y también la importancia de cruzar las categorías de género, clase y generación (Scheinkman, 2017), al mismo tiempo que estudiar el comportamiento del mercado laboral femenino (Queirolo, 2006).

A nivel internacional en el movimiento académico feminista, hoy más ampliamente, se discute el concepto de intersección. Este concepto fue acuñado por Kimberlée Crenshaw (1989: 139). Remite a estructuras de opresión múltiples y simultáneas con el fin de mostrar las diversas modalidades en que la raza y el género interactúan para dar forma a complejas discriminaciones de las mujeres negras en Estados Unidos.

También me nutro de los estudios de la admirada Silvia Federici (2010), en especial los avances que ha hecho alrededor de que los fundamentos del capitalismo se basan en la división sexual del trabajo son fundamentales para comprender, según mi punto de vista, la explotación capitalista patriarcal de las mujeres trabajadoras, su explotación específica. Pienso fervientemente que el feminismo radical de Federici debe ir de la mano de un estudio materialista dialéctico y marxista, en sentido clasista. El trabajo doméstico tout court no es el que aumenta la plusvalía general del capitalismo patriarcal a nivel del trabajo social abstracto, sino solo lo es el de las mujeres de la clase trabajadora.

Estos avances son muy fructíferos, hay que especificar la importancia de la unificación. En realidad, las intersecciones de las que he hablado no se quedan en meros cruces. Los planteos de Federici me ayudaron a pensar en estas unificaciones. Estas son realidades unificadas: la mujer negra de clase obrera es mujer, negra y de clase obrera y esta unión es la que interviene en su explotación específica. Nosotros, como científicos sociales, podemos hablar de intersección para comprender el fenómeno, pero en la realidad lo que encontramos son uniones de una infinidad de intersecciones, que el capital utiliza para su beneficio. Yo aquí me ocupo de cómo la intersección específica entre la clase y el género genera una unión inseparable que es el reflejo de la esencia unificada del patriarcado con el capitalismo, la que genera en estas obreras de principios del siglo XX estas experiencias de clase particulares, estas condiciones de explotación particulares, esta explotación específica por el capitalismo patriarcal. Posteriormente habría que ampliar los estudios e incluir la problemática de la etnia (estas obreras eran en su mayoría argentinas porque eran más baratas).

Para realizar el estudio de las experiencias de estas obreras he utilizado fuentes obreras e institucionales, ya que en 1909 se ordenó realizar un informe sobre las condiciones de trabajo en las fábricas de tejidos e hilados, con el fin de supervisar las condiciones en que 
trabajaban los obreros y obraras y comprobar si se cumplía con la Ley $5.291^{3}$-que regulaba el trabajo de mujeres y menores-. Según este informe, en los establecimientos censados se trabajaba en muy malas condiciones y se pedía una nueva inspección. ${ }^{4}$ Los problemas que he encontrado son de salubridad e higiene, de incumplimiento de la ley y, por último, de encubrimiento de trabajadoras menores. Lo que hago en los próximos apartados es analizar toda esta información para examinar las experiencias de las trabajadoras y, a través de ello, descifrar la explotación específica de las mismas.

\section{Las experiencias de clase generizada en las fábricas textiles hacia 1910}

\section{La ley que protege a las obreras no traspasa los dinteles de las fábricas}

Como he expuesto en la introducción a este trabajo, para realizarlo me baso en fuentes institucionales y obreras. La fuente institucional principal es un informe publicado en el Boletín del Departamento Nacional del Trabajo. La preocupación por la cuestión laboral floreció con el desarrollo del capitalismo (Poy, 2015) mismo en la Argentina y desde que se creó el DNT (1907) se comenzaron a realizar informes sobre las condiciones de trabajo de los distintos sectores laborales (Lobato y Suriano, 2014, Xxxx). En dicho informe se vuelca toda la información recolectada luego de hacer una investigación sobre las condiciones de trabajo de las/los trabajadores de los establecimientos textiles de la Ciudad de Buenos Aires. ${ }^{5}$

Las obreras de la industria textil y de la fábrica que me ocupa en particular, Gratry, vivían la experiencia que significaba que los patrones evadieran permanentemente la ley del trabajo que las protegía. Esta Ley -la 5.291- disponía una serie de obligaciones para los patrones y derechos para las mujeres y menores trabajadores/ as que, según el informante del DNT, “(...) no han llegado en absoluto a trasponer los dinteles de estas fábricas". ${ }^{6}$ Los/as trabajadores ejercían una constante presión hacia el Estado para asegurar lo que ellos consideraban sus derechos (Scheinkman, 2015b), de hecho también estas leyes - que parecen no haber hecho mella en el cotidiano del trabajo de las obreras- fueron pregonadas y acicateadas por los expertos y funcionarios del Estado que redirigían o querían redirigir el conflicto social hacia un terreno legal (Scheinkman, 2015b), pero ni la presión de los expertos ni la de los trabajadores lograron, como dijera el informante del DNT, que los empresarios cumplieran con las leyes y, en cierto sentido, que el Estado las hiciera cumplir. De manera que se producía una distancia política y social entre la promulgación de la ley y su implementación (Scheinkman, 2015b; Barandiaran, 2017).

La Ley 5.291 fue sancionada en 1907, luego de enfervorizados debates donde la Unión Industrial Argentina jugó un rol predominante como impugnadora de sus principales artículos, como el de la reducción de la jornada laboral de los menores y las mujeres (Mases et al., 2015). Más allá de su sanción, esta ley tuvo grandes problemas en su aplicación e implementación real, primero porque las patronales no la cumplían, segundo porque el Estado no controlaba que lo hicieran o su control padecía de una

3 Como protagonista fundamental de los debates sobre la "la cuestión social" y ante el problema cada vez mayor del trabajo femenino e infantil y la explotación brutal a la que estaban sometidos/as, Alfredo Palacios se convirtió en el mayor promotor de una ley que protegiera a estos sectores vulnerables de la población trabajadora. Así fue que en 1907 (el mismo año en que se creó el DNT) se sancionó luego de calurosos debates la Ley 5.291. Para profundizar en la temática, ver Lobato (2007b). 4 Boletín del Departamento Nacional del Trabajo, núm.12, p. 6,31 de marzo de 1910.

5 Me refiero a estos establecimientos con el criterio con que aparecen en el informe: numerados. Luego, donde hago un análisis detallado de salarios y extensión de la jornada laboral aparecen los establecimientos más especificados en una tabla, pero en estos dos primeros apartados, aparecerán como "establecimiento $\mathrm{N}^{\circ} 1, \mathrm{~N}^{\circ}$ 2, etc. Hago esta aclaración de índole metodológica para que se comprenda la utilización de la fuente.

6 Boletín del Departamento Nacional del Trabajo, núm. 12, p. 206. 
gran deficiencia y en muchos casos hasta se convirtió en infractor, y tercero porque las familias obreras necesitaban que sus hijos trabajaran y la ley en tal caso, lo permitía, por lo tanto “(...) toda esta batería de medidas legales impulsadas por el Estado, en toda esta etapa, choca con una serie de inconvenientes que terminan por esterilizar la posibilidad de combatir o al menos regular y controlar eficazmente el trabajo infantil" y femenino (Mases et al., 2015: 14).

Para analizar las experiencias laborales de las obreras, me focalicé en las mujeres trabajadoras de la industria textil, ya que con respecto a la composición por sexo de la mano de obra en esta industria, lo que se deduce de la información del Censo de la Ciudad de Buenos de 1909 es que las mujeres constituían un 79,28\% de la fuerza laboral, con un total de 5.428 obreras ${ }^{7}$ Esto abarca todos los establecimientos censados (se censaron 34 establecimientos de tejidos e hilados) y el total de las menores, ya que el documento que acompaña los datos afirma que todos los menores eran de sexo femenino. Este es un número más que representativo del sector femenino de la clase obrera.

Con respecto a los Establecimientos Americanos Gratry, se habían implantado en el país luego de la crisis de 1890, cuando empezó a crecer el sector industrial y comenzaron a instalarse empresas de capital extranjero. La fábrica argentina era una sucursal de una multinacional cuyos capitales eran belgas, y se estableció en el país en 1897 en el barrio de Nueva Pompeya, al sur de la Capital Federal, y allí se encontró en funcionamiento hasta entrada la década de 1940. En 1910, era una de las fábricas de hilado más grandes del país: empleaba a 880 obreros, de los cuales 680 eran mujeres.

Nos parece pertinente e ilustrativo mencionar algunos ejemplos concretos que hemos relevado para poder dar cuenta de las experiencias de las trabajadoras mayores y menores, tanto de esta fábrica como de todas las demás. ${ }^{8}$ Por ejemplo, en la mayoría de las fábricas, las niñas trabajaban diez horas diarias, como hemos visto, lo que supera las ocho horas que deberían hacerlo por ley. Esta era clara al respecto: "Los menores de diez y seis años no trabajarán más de ocho horas por día, ni más de cuarenta y ocho horas por semana". ${ }^{9}$ El informante del DNT decía al respecto:

Esta disposición es de las más violadas, a pesar de ser de las más difundidas; por el cuadro que acompaño se puede ver el número de fábricas que no la observan. Hay industriales que manifiestan que las menores de sus respectivas fábricas trabajan 8 horas y estas [se refiere a las niñas] aseguran no ser cierto y que trabajan 9 a 10 horas. He tenido la precaución de tomar el nombre y edad de las menores consultadas como puede verse en el registro. ${ }^{10}$

Además, tampoco constaban en el registro de menores que debían llevar todos los patrones, también los empleadores violaban la ley en este sentido, cuya letra enunciaba:

Los industriales, comerciantes o sus representantes que ocupen servicios de menores a que se refiere esta ley, estarán obligados a llevar un registro que conste su nombre y apellido, lugar y fecha de nacimiento, su residencia y los nombres, apellidos, profesión y residencia de sus padres o tutores. Estos datos serán comunicados al Ministerio de Menores. ${ }^{11}$

7 Estos números no incluyen a las obreras a domicilio. Según el informe, todas las fábricas empleaban obreras a domicilio, pero los patrones no las tenían registradas, por lo cual no se pudo relevar su cantidad (Boletín del Departamento Nacional del Trabajo, núm. 12, p. 26, 31 de marzo de 1910).

8 No examinaremos en este trabajo la problemática de los despidos por embarazo, ya que merece un artículo aparte, pero esta era una evasión más que frecuente de la ley.

9 Boletín Oficial, año XV, núm. 4177, p. 1, 17 de octubre de 1907, Ley N 5291. Reglamentación del trabajo de mujeres y menores, capítulo III, Art. $9^{\circ}$, inciso 1.

10 Boletín del Departamento Nacional del Trabajo, núm. 12, p. 209

11 Boletín Oficial, Capítulo I, Art. 3, p. 1. 
Otro elemento del que daban cuenta los informantes era que los patrones mentían respecto de la situación de las menores, por ejemplo, uno de ellos daba cuenta de lo siguiente: "El patrón me manifestó que las menores trabajan 8 horas, pero la menor Bernardina Martínez de 14 años me dijo que las menores trabajaban 10 horas", ${ }^{12}$ esto sucedía en el establecimiento $\mathrm{N}^{\circ} 10$. En el establecimiento $\mathrm{N}^{\circ} 22$, una menor fue obligada a mentir la edad por el dueño de la fábrica: “(...) hablé con la menor Luisa Daneri, quien me dijo tener 16 años, lo que no parecía y que trabajaba 10 horas". ${ }^{13}$ Con respecto al establecimiento de la calle Álvarez 1459, el informante decía lo siguiente:

Los dueños se han resistido a obedecer la ley; se le encontraron muchas niñas menores de catorce años que trabajaban diez horas diarias y sin permiso del juez resistiéndose a sacar dicho permiso y prometiendo cerrar la fábrica antes de obedecer la ley. Indico, pues, al señor jefe tomar las medidas necesarias al respecto. ${ }^{14}$

En síntesis, en la gran mayoría de los establecimientos censados las menores trabajaban diez horas y no lo que la ley establecía.

Otra de las experiencias vividas por las obreras era el hecho de trabajar en condiciones de extrema inseguridad y expuestas, por tal motivo, a todo tipo de peligros y accidentes. Por ejemplo, el Art. 7 de la Reglamentación de la Ley 5.291 dispone entre otras cosas, que toda rueda hidráulica o movida por fuerza análoga deberá estar protegida. El informante del DNT, decía con respecto a esto:

Considero, señor presidente, de la mayor importancia esta disposición que evitaría innumerables accidentes constantemente expuestos a que se produzcan y conozco el caso de una menor que perdió el dedo de una mano por haber tocado un engranaje trabajando. La mayor parte de los establecimientos no ha dado cumplimiento a esta necesaria disposición. ${ }^{15}$

La falta de espacio en la que incurría la gran mayoría de las fábricas hacía el trabajo muy peligroso. Por ejemplo: en el establecimiento $\mathrm{N}^{\circ} 3$ "en el departamento de pulverizar trapo existe una máquina llamada 'Diablo' por ser sumamente peligrosa por los incendios que produce". ${ }^{16}$ Esta máquina se encontraba en todos los establecimientos censados.

Otra de las experiencias que vivían las menores era que no se respetaba la ley en cuanto a que los industriales no se atenían a que ellas tenían que terminar su instrucción para poder trabajar. La Ley era clara al respecto: el artículo $1^{\circ}$ establecía que

No pueden ser objeto de contrato los niños mayores de diez años que comprendidos en la edad de la ley escolar, no hayan completado su instrucción obligatoria. Sin embargo, el defensor de menores del distrito podrá autorizar el trabajo de estos, cuando fuera indispensable para la subsistencia de los mismos, de sus padres o de sus hermanos. ${ }^{17}$

Según el informante esta disposición "salvo muy pocas excepciones, no se tiene en cuenta: escasos son los industriales que poseen los certificados del defensor de menores y los que lo tienen, son a menudo en número inferior a los menores que ocupan". ${ }^{18}$

12 Boletín del Departamento Nacional del Trabajo, núm. 12, p.14.

13 Boletín del Departamento Nacional del Trabajo, núm. 12, p.18.

14 Boletín del Departamento Nacional del Trabajo, núm. 12, p. 194.

15 Boletín del Departamento Nacional del Trabajo, núm. 12, pp. 208 y 209.

16 Boletín del Departamento Nacional del Trabajo, núm. 12, p. 11.

17 Boletín Oficial, núm. 12, Capítulo I, Disposiciones del Derecho Civil, Art. 1, p. 1.

18 Boletín del Departamento Nacional del Trabajo, núm., núm. 12, p. 209. 
Esta disposición también era burlada por los patrones de las fábricas de alpargatas, según el informante. El defensor de menores era quien, en última instancia, permitía o no el trabajo de los menores, siguiendo la normativa antes citada, pero esta era más bien una figura formal que raras veces actuaba sobre la realidad concreta, es más, muchas veces hasta el mismo defensor transgredía la ley (Mases et al., 2015). Desde los comienzos de la industrialización en la Argentina el empleo de menores -y en este caso de niñas - se fue incrementando porque, como en el caso de las mujeres mayores era una mano de obra más barata (Queirolo, 2010). En cuanto a los niños de la clase obrera, la representación niño/alumno chocaba con la realidad del niño, en este caso niña/trabajadora, lo que generaba muchas contradicciones (Queirolo, 2010). He visto en el informe del DNT que a las niñas, además de hacerlas trabajar, se las hacía cumplir sus tareas completamente en la ilegalidad:

En todos los establecimientos que he visitado, prestan sus servicios 191 niños de 10 a 14 años, de los que solo 3 tienen la necesaria autorización y los 188 restantes no la tienen, unos porque ignoran ellos y sus padres que tienen obligación legal de sacarla, y otros, porque y aun cuando el industrial y el niño que ofrece su trabajo saben que no pueden ocuparse sin ese requisito, hacen caso omiso de ello porque no ha habido una inspección inteligente y bien intencionada que haya hecho cumplir lo que la ley dispone. ${ }^{19}$

Es decir, el 98,4\% de las fábricas evadían la ley y solo el 1,5\% la acataban y, en este último caso, lo hacían a medias. Gratry era una de las tres fábricas más grandes. Al estudiar la documentación he deducido que Gratry era el establecimiento $\mathrm{N}^{\circ} 5$ del informe del censo industrial porque lo conocía por investigaciones previas. Esta fábrica tenía características particulares: empleaba, desde los inicios de su funcionamiento, alrededor de 800 obreros y contaba con un edificio, "los conventillos", construido por los mismos dueños, que estaba dentro del predio de la fábrica y que los alquilaba a los trabajadores del establecimiento, lo que consta en el informe realizado por el DNT.

En esta fábrica también se violaba constantemente la Ley 5.291, La Vanguardia describe la fábrica de Nueva Pompeya como una "nueva cárcel industrial". ${ }^{20}$ Y comenta:

[...] El horario de trabajo es de 10 horas y media como mínimun. Las multas se aplican por cualquier pretexto. Las suspensiones son la norma de los capataces. El trabajo a destajo es extenuante y en la medición de las telas es regla establecida anotar un $20 \%$ menos de su total exacto. La ley que reglamenta el trabajo de mujeres y niños es violada descaradamente, ocultándose a los menores cuando de casualidad llega algún inspector oficial. La fábrica tiene en el radio de su propiedad habitaciones que alquila a los obreros a razón de pesos 3,25 semanales; el pago es adelantado. Estas piezas tienen $3 \times 4$ y por su frente cruzan canaletas de residuos que exhalan olores nauseabundos. [...]. ${ }^{21}$

Para resumir, cito las palabras de un funcionario del DNT que también son claras al respecto. Joaquín Ávalos comenta lo siguiente sobre las tejedurías e hilanderías:

Esta industria es la que emplea en mayor escala el trabajo de mujeres y menores. Con respecto a estas últimas puedo afirmar, sin exageración alguna, que puede aumentarse en un $30 \%$ el número de las que figuran en el registro, pues he confirmado que los patronos muy comúnmente ocultan la verdad al dar esta información. ${ }^{22}$

19 Op. cit., p. 211.

20 "En el Establecimiento Gratry”, LV, 26 de marzo de 1910, año XVI, núm. 1304, p. 1.

21 lbídem.

22 lbídem, p. 206. 
Los industriales no se atenían a la Ley 5.291 que regulaba el trabajo de mujeres y niños. Con respecto a esto encontré las siguientes consideraciones en el informe de Joaquín Ávalos:

La ley de trabajo de mujeres y niños es a los obreros de este gremio a los que más directamente ampara. Sin embargo los beneficios de ella no han llegado en absoluto a trasponer los dinteles de estas fábricas. Puedo afirmar que la casi totalidad de los artículos de esta ley que tienen atingencia con las obreras y menores, no son conocidos por los patrones y si lo son, nadie se ha ocupado de ponerla en práctica. ${ }^{23}$

Estas eran las condiciones de trabajo que experimentaban las obreras de la industria textil y que, sin duda, forman parte de su explotación específica, como mujeres.

\section{Las obreras y sus salarios}

En este apartado analizaré la experiencia de las obreras en lo que respecta a las diferencias salariales con los obreros. Las mujeres y los hombres se proletarizan en tanto tales y una de las manifestaciones de esta diferencia en la forma de entrar en las relaciones sociales de la producción social es la desigualdad salarial, disparidad que es fundamental, ya que conlleva una diferencia en la relación con la burguesía en tanto clase explotadora, es decir, genera una agudización del antagonismo de clase generizada que, si bien afecta más a las mujeres, como daré cuenta, perjudica a la clase generizada en su totalidad, otra razón más por la que he definido a esta sociedad como capitalista patriarcal y por la que hay que unificar y hablar de explotación específica y señalar el punto donde se cristaliza la intersección entre clase y género.

Esta diferencia también genera una manera distinta de extracción de plusvalía. Todas estas desigualdades producen una experiencia de clase particular de las mujeres condicionada por el sexo-género, y por las normas socioculturales construidas por el capitalismo patriarcal. En lo que sigue, haré un análisis detallado de estas diferencias salariales para examinar concretamente las experiencias en la realidad femenina.

El salario de las mujeres en la industria textil era de menos de la mitad del masculino. Los hombres, contabilizando las 34 fábricas censadas, percibían en promedio hasta $\$ 4,29$, en cambio las mujeres podían obtener $\$ 1,87,{ }^{24}$ es decir los hombres ganaban en promedio un $129 \%$ más que las mujeres. Lo que acabo de plantear es un promedio que, por lo tanto, no da cuenta de las grandes diferencias reales y particulares, por lo tanto, presentaré una tabla con información más detallada de los sueldos máximos, mínimos y promedios de varones y mujeres y el porcentaje de las diferencias salariales correspondientes (Tabla $\mathrm{N}^{\circ} 1$ ). En algunos establecimientos la diferencia era mucho mayor, un ejemplo claro es la fábrica donde se produjo la huelga durante el ascenso huelguístico del Centenario: Gratry (Norando, 2018a); allí, las mujeres ganaban como máximo \$2,75 y los hombres, \$ 10 , o sea que estos ganaban un $264 \%$ más que las mujeres (ver Tabla $\mathrm{N}^{\circ} 2$ ). Todo esto es un ejemplo de cómo inciden las diferencias de sexo-género en la proletarización de mujeres y varones. A ello, hay que agregar que las mujeres seguían haciendo su trabajo no remunerado: el trabajo doméstico por este ínfimo salario y los varones no, pero aclaro, no son los varones individualmente, los que explotan a las mujeres, porque no es para ellos para quienes trabajan.

23 Boletín del Departamento Nacional del Trabajo, núm. 12, p. 207.

24 La documentación consultada indica unos rangos máximo y mínimo de salarios para los hombres y mujeres según cada establecimiento sin especificar un promedio y con una importante brecha entre ellos. Por ejemplo, en el establecimiento $\mathrm{N}^{\circ} 4$, sabemos que 53 varones percibían entre $\$ 2,50$ y $\$ 12$. Sin embargo, estos resultan indicativos de la gran diferencia entre los sexos, por ejemplo ninguna menor percibía más de \$2,50 siendo este máximo mucho mayor que el habitual. Para un mejor análisis de los datos hemos calculado los promedios. 
Tabla № 1. Fábricas de Tejidos e Hilados de Buenos Aires

Cantidad de obreros desagregados por sexo y edad, marzo de 1910.

\begin{tabular}{|c|c|c|c|c|c|c|c|c|}
\hline \multirow[b]{2}{*}{$\begin{array}{l}\quad \mathrm{N}^{\circ} \text { de } \\
\text { identificación del } \\
\text { establecimiento* }\end{array}$} & \multicolumn{4}{|c|}{ Obreros/as } & \multicolumn{4}{|c|}{ Porcentajes } \\
\hline & $\begin{array}{l}\text { Mujeres } \\
\text { mayores }\end{array}$ & $\begin{array}{l}\text { Mujeres } \\
\text { menores }\end{array}$ & Varones & Totales & $\begin{array}{c}\text { Mujeres } \\
\text { mayores } \\
\%\end{array}$ & $\begin{array}{c}\text { Mujeres } \\
\text { menores\% }\end{array}$ & $\begin{array}{c}\text { Mujeres } \\
\text { total } \\
\%\end{array}$ & $\begin{array}{c}\text { Varones } \\
\text { total } \\
\%\end{array}$ \\
\hline $\mathrm{N}^{\circ} 2 \mathrm{O}^{* *}$ & $-\cdots--$ & $-\cdots--$ & $-\cdots$ & ---- & $-\cdots--$ & $-\cdots--$ & ---- & $-\cdots$ \\
\hline $\mathrm{N}^{\circ} 12$ & 15 & 15 & 0 & 30 & 50 & 50 & 100 & 0 \\
\hline $\mathrm{N}^{\circ} 13$ & 4 & 14 & 12 & 30 & 13,33 & 46,67 & $60 \%$ & 40 \\
\hline$N^{\circ} 19$ & 20 & 7 & 5 & 32 & 62,50 & 21,88 & 84,38 & 15,63 \\
\hline $\mathrm{N}^{\circ} 27$ & 25 & 7 & 4 & 36 & 69,44 & 19,44 & 88,89 & 11,11 \\
\hline $\mathrm{N}^{\circ} 33$ & 30 & 6 & 0 & 36 & 83.33 & 16,67 & 100 & 0 \\
\hline$N^{\circ} 10$ & 15 & 15 & 7 & 37 & 40,54 & 40,54 & 81,08 & 18,92 \\
\hline $\mathrm{N}^{\circ} 30$ & 18 & 17 & 2 & 37 & 48,65 & 45,95 & 94.59 & 5,41 \\
\hline $\mathrm{N}^{\circ} 15$ & 20 & 20 & 4 & 44 & 45,45 & 45,45 & 90,91 & 9,09 \\
\hline$N^{\circ} 27$ & 36 & 0 & 10 & 46 & 78,26 & 0 & 78,26 & 21,74 \\
\hline $\mathrm{N}^{\circ} 31$ & 10 & 9 & 30 & 49 & 20,41 & 18,37 & 38,78 & 61,22 \\
\hline $\mathrm{N}^{\circ} 29$ & 21 & 0 & 29 & 50 & 42,00 & 0 & 42 & 58,00 \\
\hline $\mathrm{N}^{\circ} 21$ & 35 & 14 & 5 & 54 & 64,81 & 25,93 & 90,74 & 9,26 \\
\hline$N^{\circ} 23$ & 25 & 38 & 2 & 65 & 38,46 & 58,46 & 96,92 & 3,08 \\
\hline $\mathrm{N}^{\circ} 18$ & 50 & 15 & 11 & 76 & 65,79 & 19,74 & 85,53 & 14,47 \\
\hline $\mathrm{N}^{\circ} 26$ & 32 & 24 & 20 & 76 & 42,11 & 31,58 & 73,68 & 26,32 \\
\hline $\mathrm{N}^{\circ} 16$ & 80 & 5 & 2 & 87 & 91,95 & 5.75 & 97,70 & 2,30 \\
\hline $\mathrm{N}^{\circ} 17$ & 40 & 45 & 7 & 92 & 43,48 & 48,91 & 92,39 & 7,61 \\
\hline $\mathrm{N}^{\circ} 14$ & 18 & 62 & 16 & 96 & 18,75 & 64.58 & 83,33 & 16,67 \\
\hline $\mathrm{N}^{\circ} 8$ & 100 & 10 & 0 & 110 & 90,91 & 9,09 & 10 & 0 \\
\hline $\mathrm{N}^{\circ} 32$ & 119 & 0 & 25 & 144 & 82,64 & 0 & 82,64 & 17,36 \\
\hline $\mathrm{N}^{\circ} 9$ & 148 & 25 & 0 & 173 & 85,55 & 14,45 & 100 & 0 \\
\hline $\mathrm{N}^{\circ} 6$ & 8 & 0 & 188 & 196 & 4,08 & 0 & 4,08 & 95,92 \\
\hline $\mathrm{N}^{\circ} 11$ & 150 & 70 & 0 & 220 & 68,18 & 31,82 & 100 & 0 \\
\hline $\mathrm{N}^{\circ} 2$ & 150 & 18 & 65 & 233 & 64.38 & 7,73 & 72,10 & 27.90 \\
\hline $\mathrm{N}^{\circ} 28$ & 250 & 30 & 6 & 286 & 87,41 & 10,49 & $97,90 \%$ & 2,10 \\
\hline $\mathrm{N}^{\circ} 7$ & 77 & 20 & 225 & 322 & 23,91 & 6,21 & 30,12 & 69,88 \\
\hline $\mathrm{N}^{\circ} 4$ & 230 & 82 & 53 & 365 & 63,01 & 22,47 & 85,48 & 14.52 \\
\hline $\mathrm{N}^{\circ} 3$ & 290 & 29 & 58 & 377 & 76,92 & 7,69 & 84,62 & 15,38 \\
\hline $\mathrm{N}^{\circ} 22$ & 360 & 0 & 40 & 400 & 90 & 0 & 90 & 10 \\
\hline $\mathrm{N}^{\circ} 25$ & 250 & 10 & 150 & 410 & 60,98 & 2,44 & 63,41 & 36,59 \\
\hline$N^{\circ} 1$ & 450 & 135 & 225 & 810 & 55,56 & 16,67 & 72,22 & 27,78 \\
\hline $\mathrm{N}^{\circ} 5$ & 600 & 80 & 200 & 880 & 68,18 & 9,09 & 77,27 & 22,73 \\
\hline $\mathrm{N}^{\circ} 34$ & 728 & 202 & 275 & 1.205 & 60,41 & 16,76 & 77,18 & 22,82 \\
\hline Totales & 4404 & 1024 & 1676 & 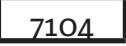 & 57,62 & 21,66 & 79,28 & 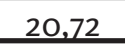 \\
\hline
\end{tabular}

Fuente: Norando (2018b).25

Elaboración propia en base a datos del Censo Industrial de 1909.

* He ordenado los establecimientos por el número de trabajadores/as empleados/as de menor a

mayor.

** Este establecimiento estaba cerrado al momento del censo, puede haber ocurrido que se tratara de un taller. Eso dan a entender los informantes.

25 Boletín del Departamento Nacional del Trabajo, pp. 8-9. Se consideraban mujeres menores a las niñas de menos de 16 años de edad. Con respecto al establecimiento $N^{\circ} 20$, este taller no estaba en funcionamiento cuando fue realizado el censo. 
Como se puede ver en la Tabla $\mathrm{N}^{\circ} 1$, de las 34 fábricas censadas en $2(7 \%)$ los varones llegaban a obtener más del 50\% que las mujeres, en $16(53 \%)$ más del $100 \%$, en $10(34 \%)$ más del $200 \%$, en 1 (3\%) el 300\% y en otra el $400 \%$ (3\%). Es decir, en más del $80 \%$ de los casos los varones llegaban a ganar hasta el $250 \%$ más que las mujeres y esta diferencia salarial es de suma importancia si recalcamos además que se daba en el rango de salarios más bajos, es decir los más frecuentes. Lo que da cuenta de que la gran mayoría de las mujeres de la industria textil experimentaba esta diferencia salarial. Con respecto a Gratry, La Vanguardia describía la fábrica de Nueva Pompeya como una "cárcel industrial”. ${ }^{26} \mathrm{Y}$ comenta: “(...) hombres, mujeres y niños están sujetos a una tiranía patronal que subleva por lo torpe y baja. La empresa destina 4.800 pesos semanales para pagar los jornales de 860 obreros." ${ }^{27}$ Esta fábrica estaba dentro del $34 \%$ de los establecimientos censados en donde la diferencia salarial era de más del $200 \%$. En la siguiente tabla vuelco los detalles de este:

Tabla $N^{\circ}$ 2. Industria textil. Diferencia salarial por sexo. Comparación promedio general máximo y Gratry. Ciudad de Buenos Aires, 1909.

\begin{tabular}{|c|c|c|c|}
\hline Establecimientos & Mujeres & Varones & Diferencia en \% \\
\hline $\begin{array}{c}\text { Promedio } \\
\text { máximo }\end{array}$ & $\$ 2,66$ & $\$ 5,68$ & 113 \\
\hline Gratry & $\$ 2,75$ & $\$ 10$ & 264 \\
\hline \multicolumn{2}{|r|}{ Fuente: elaboración propia en base a datos del Censo Industrial de 1909.28 } \\
\hline
\end{tabular}

Esta desigualdad salarial producía una experiencia de clase femenina particular, proveniente de una explotación específica. Más allá de las malas condiciones de vida que experimentaban estas obreras por sus bajos salarios y la inferioridad en las que las sumía con respecto a los varones, aquí me voy a centrar en otra experiencia: la de la diferencia de sexo-género al interior de la clase obrera, que se manifestaba en distintos aspectos. Primero, a causa de sus bajos salarios, las mujeres eran vistas por los varones como una competencia desleal y sufrían esta situación; segundo, sus salarios al ser más bajos eran vistos por los varones y por la sociedad en general como complementarios. El hecho de que las mujeres ganaran menos no solo convertía sus salarios en complementarios, sino que también transformaba a la mujer en complementaria del varón, todas sus actividades se veían como complementarias. Por ejemplo, si la mujer participaba como militante se consideraba que estaba "ayudando" al varón a conseguir determinadas reivindicaciones. Y tercero, las mujeres eran superexplotadas o sobreexplotadas por el hecho de que sus salarios eran inferiores, por lo cual la plusvalía extraída por el capital era superior a la extraída a los varones, agregándole el trabajo doméstico, mucho mayor.

La mujer trabajadora tiene una parte de su jornada laboral en la fábrica. El ejemplo que daré al respecto es actual porque los datos que siguen son actuales. En Gratry las mujeres trabajaban 10 horas (ver Tabla $\mathrm{N}^{\circ}$ 3), luego volvían a la casa y tenían que dedicarse a las tareas del trabajo doméstico. Una estimación de la cantidad de horas dedicadas al trabajo doméstico de las mujeres empleadas ${ }^{29}$ ha llegado a la conclusión de que ellas dedican alrededor de cincuenta horas a la casa por semana (Girar, 1968); otros estudios de la Argentina (Rodríguez Enríquez, 2015) demuestran que las mujeres empleadas ${ }^{30}$ ocupan 44,8 horas por semana en las tareas del trabajo doméstico no

26 “En el Establecimiento Gratry”, LV, año XVI, N 1.304, 26 de marzo de 1910, p. 1. 27 lbídem.

28 Boletín del Departamento Nacional del Trabajo, núm. 12, pp. 8 y 9.

29 Sin especificar industrias o servicios.

30 También sin especificar industrias o servicios. 
remunerado (como se puede observar, es muy estrecha la diferencia de tiempo, es decir las mujeres empleadas emplean 7 horas por día en el trabajo doméstico. Así como también se calculó el tiempo social promedio a nivel país: 5,7 horas por día (INDEC, 2013). A principios de siglo no existían los electrodomésticos que facilitan y ahorran tiempo de trabajo del hogar como lavadoras automáticas, aspiradoras, etc., así es que agrego una hora más a los cálculos actuales. Los valores monetarios de estas actividades también están analizados en otros países, por ejemplo, en Perú se hizo un estudio a nivel nacional gracias al cual se concluyó que el trabajo doméstico de las mujeres peruanas no remunerado vale 31.121 millones de dólares anuales, 101.621 millones de soles al año (ENUT, 2010).

Tabla N 3. Horas de trabajo por día de mujeres y niñas en hilados y

tejidos, 1909

\begin{tabular}{|c|c|c|c|c|c|c|c|c|}
\hline $\begin{array}{l}\text { Estable- } \\
\text { cimiento }\end{array}$ & $\begin{array}{c}\text { Horas } \\
\text { de } \\
\text { trabajo } \\
\text { de las } \\
\text { mujeres }\end{array}$ & $\begin{array}{l}\text { Horas } \\
\text { de } \\
\text { trabajo } \\
\text { de las } \\
\text { niñas }\end{array}$ & $\begin{array}{l}\text { Estable- } \\
\text { cimiento }\end{array}$ & $\begin{array}{c}\text { Horas de } \\
\text { trabajo } \\
\text { de las } \\
\text { mujeres }\end{array}$ & $\begin{array}{c}\text { Horas } \\
\text { de } \\
\text { trabajo } \\
\text { de las } \\
\text { niñas }\end{array}$ & $\begin{array}{l}\text { Estable- } \\
\text { cimiento }\end{array}$ & $\begin{array}{c}\text { Hs. } \\
\text { Trabajo } \\
\text { Mujeres }\end{array}$ & $\begin{array}{c}\text { Horas de } \\
\text { trabajo } \\
\text { de las } \\
\text { niñas }\end{array}$ \\
\hline 1 & 10 & 9 & 13 & 10 & 10 & 25 & 9 & 9 \\
\hline 2 & 9 & & 14 & 9 & 10 & 26 & 9 & 8 \\
\hline 3 & 10 & 10 & 15 & 10 & 9 & 27 & 10 & 10 \\
\hline 4 & 9 & 10 & 16 & 10. & 9 & 28 & 9. & 9 \\
\hline 5 Gratry & 10 & $101 / 2$ & 17 & 10 & 10 & 29 & 10 & --- \\
\hline 6 & $10^{1 / 2}$ & 9. & 18 & 10 & 8 & 30 & 10 & 9 \\
\hline 7 & 10 & $9^{1 / 2}$ & 19 & 9 & 8 & 31 & 10 & 10 \\
\hline 8 & 9. & ---- & 20 & ------ & ----- & 32 & 10 & 10 \\
\hline 9 & $9^{1 / 2}$ & $9^{1 / 2}$ & 21 & 10 & ---- & 33 & 10 & 10 \\
\hline 10 & 10 & 10 & 22 & 10 & 10 & 34 & 10 & 10 \\
\hline 11 & 9 & 8 & 23 & 9 1/2. & 10. & & & \\
\hline 12 & 8 & 9 & 24 & 10 & $9^{1 / 2}$ & & & \\
\hline
\end{tabular}

Fuente: elaboración propia en base a datos del Censo Industrial de 1909.31

Por desgracia no cuento con datos precisos para el período de mi estudio. Pero puedo estimar algunas variables. Las obreras textiles trabajaban en la fábrica 10 horas, el tiempo estimado del trabajo doméstico concreto son 8 horas por día, por lo tanto, las obreras textiles tenían una jornada laboral de 18 horas diarias repartidas de la siguiente manera: 10 en trabajo asalariado y 8 en trabajo gratuito por día. Las dos partes de la jornada las debían cumplir absolutamente todos los días porque la Ley del Descanso Dominical, sancionada en 1904, no se cumplía (Norando, 2018a). Por esta gran jornada laboral solo dividida por el espacio (porque recuerdo que mi categoría de análisis es su fuerza de trabajo) a las obreras textiles de principios del siglo XX les pagaban un salario que - según fuentes oficiales - en Gratry, era en promedio de \$

31 Como he mencionado antes, este establecimiento no estaba en funcionamiento en el momento del censo. 
$2,75.32$ Pero quiero reflejar estas cuestiones en números claros para transmitir y dar cuenta más concretamente de la situación de estas trabajadoras. Lo que estoy explicitando se puede corroborar a partir de los datos del DNT sobre el costo de los bienes de consumo de subsistencia y el costo habitacional de la clase obrera para diciembre de 1910 y diciembre de 1911. Luego de hacer un análisis de los datos publicados por el Departamento, podemos afirmar que una familia obrera con tres hijos necesitaba $\$ 161,62$ para cubrir sus gastos en comida 33 y $\$ 18$ por mes para cubrir los gastos de vivienda. ${ }^{34}$ Lo que como mínimo necesitaba una familia obrera para subsistir eran \$179,62. No está de más decir que el tipo de vivienda que podían alquilar con este monto era una habitación de $5 \times 4 \mathrm{~m}$, sin cocina. De estos inquilinatos el informante comentaba lo siguiente:

Las condiciones higiénicas en general, son malas. Los recursos con los que cuentan las familias no son suficientes para poder tomar otra habitación más. Esto último me hace decir que en este país el obrero vive mal y en condiciones poco favorables para la higiene y la moral" 35 Había casitas para obreros en los mismos barrios, pero los informantes del DNT decían "Hay casitas en la vecindad de dos o tres piezas, los que no son ocupados por obreros, sino por empleados" ${ }^{36}$

Entonces el presupuesto de una familia para subsistir debía ser como mínimo de \$ 179,62. Efectivamente, el salario de las obreras, según indican todos los números (\$ 85,25 mensuales) tomando como referencia 31 jornadas laborales porque no se cumplía con el descanso dominical, el salario de las mujeres textiles se ubicaba muy por debajo del costo de vida que la repartición estatal reconocía: por un lado, \$ \$161, 62 para comida y \$ 18 para el alquiler de una habitación obrera. O sea, ni los varones ni las mujeres cubrían el costo de vida y puede considerarse como causal la existencia del trabajo doméstico gratuito, pero no solo por su sola existencia sino por el mecanismo de explotación específica que genera sobre las mujeres. Así y todo "el trabajo doméstico constituye una gran cantidad de producción socialmente necesaria que $\sin$ embargo no está considerada como trabajo real" (Rowbotham, 1977; Artous, 1982).

La extensa jornada laboral permitía que los salarios de la clase trabajadora textil argentina de aquel entonces fueran extremadamente bajos y sobre todo los de las mujeres, ya que a ellas se les pagaba siempre un porcentaje menor que a los varones, como he mostrado más arriba y demostrado en mis estudios de caso, se les pagaba un salario irrisorio (ver gráfico $\mathrm{N}^{\circ} 1$ ).

Gráfico № 1. Jornada de trabajo de una obrera textil en 1910, salario y plusvalía.

\begin{tabular}{|c|c|}
\hline $\begin{array}{c}\text { Salario } \\
4 \text { horas }\end{array}$ & $\begin{array}{c}\text { Plusvalor por trabajo asalariado y por trabajo } \\
\text { doméstico } \\
4 \text { horas }\end{array}$ \\
\hline Jornada de 18 horas de trabajo
\end{tabular}

De más está decir, como se ve gráficamente y como lo he demostrado con estudios empíricos, que a las mujeres obreras su salario jamás les ha alcanzado para subsistir, por lo menos a las textiles: desde principios del siglo XX y hasta 1946, no podían subsistir con él (Norando y Scheinkman, 2011; Norando, 2013, 2018a y b). Lo que sucede es que justamente este salario encubría una cantidad de trabajo gratuito aplicado a

32 Censo Industrial de 1909.

33 Boletín del Departamento Nacional del Trabajo, núm. 18, pp. 593-595, 30 de septiembre de 1911.

34 Boletín del Departamento Nacional del Trabajo, núm. 15, pp. 846-863,31 de diciembre de 1910.

35 Boletín del Departamento Nacional del Trabajo, núm. 15, pp. 850-861, 31 de diciembre de 1910.

36 Ibídem, p. 851. 
lograr su subsistencia (y la de los varones). Es decir, este salario encubría un no-salario o un salario que no se pagaba por un trabajo que efectivamente se hacía y que es el principal motor de la explotación capitalista, justamente por eso pudo y puede no pagarse. En el capitalismo patriarcal entonces el salario encubre un trabajo gratuito que hace que esa retribución por el total y para toda la población trabajadora en general sea cada vez más baja.

\section{El quehacer del trabajo doméstico: demandas y movilización}

Los varones experimentaban la incorporación de las mujeres a la industria como una competencia desleal. El hecho de que se viera a la mujer trabajadora como una competencia tiene una razón principal y es de carácter económico: que la mano de obra femenina, en este período, iba en aumento y tendía a reemplazar a la masculina por la incorporación cada vez mayor de máquinas que permitían la descalificación del trabajo y la simplificación de las tareas. Y como a las mujeres se les pagaba menos por el mismo trabajo, hipotéticamente eran las preferidas por los patrones a la hora de contratar mano de obra, con el consabido aumento del ejército de reserva de mano de obra masculina y la reducción de los salarios de todos en general. Todo lo anterior provoca que aumente la masa de plusvalía. Además, este reemplazo de hombres por mujeres también atentaba contra el lugar de los varones en la fábrica y, consecuentemente, en sus funciones de proveedores del hogar, en su poder y autoridad dentro de las familias, acarreando todo ello una mengua en su identidad varonil. Este temor a la competencia femenina tiene su base concreta en la realidad de la especificidad de la proletarización de la mujer, que constituye una mano de obra subcalificada, que percibe salarios más bajos y que, con la incorporación de maquinaria (que descalifica el trabajo), es más susceptible de ser contratada.

Las mujeres vivían esto con el peso que significaba que un sector del movimiento obrero organizado sopesara seriamente la posibilidad de que las mujeres no debían trabajar, sobre todo en las industrias. En 1889, el Congreso Obrero de París resolvió prohibir el trabajo de las mujeres "en todas las ramas que afecten con particularidad el organismo femenino". Esta cláusula fue trasladada al manifiesto que, un año más tarde, el Comité Internacional Obrero realizaba en nuestra ciudad (Oddone, 1975: 87). En el Primer Congreso de la Federación Obrera Argentina (1901), se votó una resolución que prohibía el trabajo de las mujeres en lo que pudiera constituir “(...) un peligro para la maternidad o un ataque a la moral" (Bilsky, 1985: 192). Otro tipo de prohibición parcial que reclamaban los obreros (varones), fue el trabajo nocturno de las mujeres, cualquiera fuera la actividad que realizaran (mientras que, en el caso de los obreros varones, solo se prohibía en determinadas ramas).

Otras propuestas fueron más allá de las prohibiciones parciales alegando motivos fisiológicos y/o morales, en el IV Congreso de la Unión General de Trabajadores (UGT) se propuso la supresión total del trabajo de las mujeres en las fábricas. ${ }^{37}$ Igualmente este era un debate dentro del Partido Socialista y la "prohibición total" no logró nunca ser la posición dominante a su interior, en realidad su principal demanda se orientó hacia la "reglamentación" del trabajo femenino y la igualdad salarial con los hombres, aceptando de hecho su existencia. Sin embargo, su posición nunca fue clara, especialmente en ciertas coyunturas cuando se filtraba entre los obreros el temor de ser reemplazados por las mujeres en las fábricas. Por ejemplo, en 1907, La Vanguardia reclamaba que el trabajo femenino debía ser prohibido en algunas industrias, específicamente en aquellas que se consideraban nocivas para la capacidad reproductiva y/o la moralidad de las mujeres. Las prohibiciones totales, $37 \mathrm{LV}, 13$ de diciembre de 1906. 
por otra parte, solo se referían al trabajo fabril. La familia era considerada como el verdadero lugar de la mujer y la maternidad como su función esencial.

En la perspectiva de los varones, el trabajo femenino era perjudicial para las nuevas generaciones y producía desocupación masculina, por lo tanto, según ellos la solución óptima habría sido su supresión total, pero la realidad se imponía, el trabajo femenino era necesario no meramente complementario en la mayoría de las familias obreras.

Las mujeres en esta época tenían muy poca militancia sindical, esto no quiere decir que no participaran en los conflictos contra el capital patriarcal, como he analizado en estudios de caso previos; de hecho, tenían una participación masiva en las huelgas (Norando y Scheinkman, 2011; Norando, 2018a y b). Pero hasta promediada la década de 1930, tuvieron poca militancia orgánica en las organizaciones obreras, lo que las dejaba fuera de las decisiones en lo que respecta a las reivindicaciones del movimiento obrero de la época (Norando, 2018a). Lo que vengo explicitando sobre las posturas adoptadas por el movimiento obrero del período con respecto al trabajo femenino eran posiciones masculinas, las obreras no participaban en estas decisiones. En la industria textil, donde la mano de obra femenina constituía alrededor del $70 \%$, ellas vivían la experiencia de no poder tomar ninguna decisión sobre su propio trabajo. El hecho de que hubiera propuestas de supresión del trabajo femenino es una muestra de esto, ellas nunca hubieran propuesto esto ya que era una necesidad propia.

Las obreras también eran vistas como complemento de los obreros. Esto tiene una razón económica porque en ellos estaba asumido que el salario de la mujer, al ser menor, complementaba al del hombre. Ya que el trabajo de la mujer era visto como complementario y transitorio, esto también era parte de las características de la proletarización de la mujer en tanto tal. El ideal era que la mujer trabajara únicamente si lo necesitaba el grupo familiar y, en caso de que así fuera, lo hiciera solo hasta el matrimonio, ideal que se mantuvo durante toda la primera mitad del siglo XX. ${ }^{38}$ Aunque esta no era la realidad porque la experiencia de las trabajadoras era que, en numerosas oportunidades, por ejemplo, trabajaban hasta el nacimiento del primer hijo, a veces hasta el del segundo, y en la mayoría de los casos nunca dejaban la fábrica. Si seguían trabajando luego de las nupcias, su salario era visto como un complemento, no era considerado el sustento del hogar obrero, solo era una ayuda al salario masculino, que era el que verdaderamente proveía de sustento a la familia.

Por un lado, este discurso reforzaba la desigualdad salarial material entre hombres y mujeres, que era un dato de la realidad concreta, por ejemplo, en la huelga de la casa Gratry se exigía aumento de salario, pero no se pedía la igualación del salario femenino con el masculino (Norando, 2018b). Y, por otro lado, reafirmaba la norma genérica por la cual el hombre era el proveedor indiscutido del hogar, que afianzaba las relaciones asimétricas de poder contenidas en las relaciones sociales de género en el mundo capitalista. Las mujeres obreras de la industria textil vivían esta experiencia particular a causa de su condición sexual, la de ser consideradas un complemento del sexo masculino. Esta condición particular muchas veces ha hecho que el Estado tuviera que intervenir y de hecho proveer políticas publicas que, en cierta medida fueran tendientes a alivianar la pesada carga que recaía sobre las mujeres (Boris y Klein, 2006; Norando, 2018a).

Las mujeres sufrían una explotación específica, ya que se les pagaba hasta el $400 \%$ menos que a los varones por una jornada laboral extensísima. Por lo tanto, la plusvalía extraída del trabajo de las mujeres era mucho mayor que la extraída a los varones por

38 Para un análisis más amplio del tema, ver Norando, "El Obrero textil..." op.cit. <HAY DOS OBRAS CON ESE TÍTULO, 2011a y 2011b. ¿A CUAL SE REFIERE?> YA LO CORREGí 
su condición sexual. Esto demuestra que en la sociedad contemporánea las diferencias de género están al servicio del capital.

\section{Entonces, ¿por qué las obreras viven una experiencia de clase parti- cular y son víctimas de una explotación específica?}

La experiencia de clase de las mujeres está profundamente condicionada por su lugar en la división sexual del trabajo. La relación de las mujeres con el capital es fundamentalmente la de producir y reproducir la fuerza de trabajo presente y futura de la que depende toda la explotación capitalista por medio del trabajo doméstico impuesto a las mujeres por la división sexual del trabajo asignada a hombres y mujeres por el modo de producción capitalista patriarcal.

Esta es la esencia del trabajo doméstico y este es el trabajo para el que se prepara a la mayoría de las mujeres, en especial, a las mujeres trabajadoras, pero también por el que se identifica a toda mujer (Dalla Costa, 1972). Voy a profundizar sobre este matiz importante. Las mujeres trabajadoras están predestinadas a realizar el trabajo doméstico, las mujeres de la burguesía pueden escapar de él, pero no así de su organización, ellas se convierten en patronas del trabajo doméstico de sus empleadas. Es decir, la mujer trabajadora carga con este trabajo que reproduce la sociedad y aumenta la plusvalía, la mujer burguesa ayuda a reproducirla, pero hay una diferencia de clase irreductible, es su patrona. Esto es, las obreras de la industria textil en particular están dentro de este grupo, son aquellas que con su fuerza de trabajo producen y reproducen la sociedad.

Discuto fervientemente con afirmaciones como esta: "Así, la clase obrera está dividida por el poder de aquellos cuyo trabajo es asalariado (hombres) ejercido sobre aquellos cuyo trabajo no es asalariado (mujeres)" (Dalla Costa, 1972: 25 ¿página?). La clase obrera no está dividida por el sistema patriarcal como si fuera un solo sistema separado del sistema capitalista, sino que está explotada omnia por el capital patriarcal. La jerarquía familiar, el trabajo doméstico y el asalariado en unión son las bases del capitalismo patriarcal y producen y reproducen el sistema en forma conjunta y unificada. En este trabajo creo haberlo demostrado en los apartados anteriores. La producción social depende totalmente de la parte de la jornada no remunerada que corresponde al trabajo doméstico de las mujeres de la clase obrera. La parte de la jornada laboral no remunerada de la mujer trabajadora no es reconocida como trabajo, ni siquiera por las mujeres mismas, no está remunerada y, cómo he desarrollado, es uno de los principales factores del aumento de la plusvalía a nivel general, aunque sea un trabajo precapitalista, más allá de que antaño se haya discutido demasiado sobre si este trabajo producía valor o plusvalor, si era un plusvalor directo o indirecto, etc.

Aquí sostengo que esta parte de las jornadas de las mujeres de la clase trabajadora genera plusvalía directamente, no hace falta que exista contrato con el capitalista para que le expropien su trabajo y haga uso de su fuerza de trabajo y que no es el marido quien la explota, sino el capital patriarcal. ¿Por qué? Porque la jornada de trabajo de la mujer que trabaja dentro y fuera de su casa es una sola, trabaja una parte dentro de su hogar (hace el trabajo doméstico que reproduce y produce fuerza de trabajo y la vida en general de toda la sociedad) y trabaja otra parte de su jornada laboral afuera, en cualquier tipo de establecimiento. Me refiero con mujeres trabajadoras a aquellas a las que no les alcanza con su salario (o el del marido) para pagar el trabajo doméstico de otra mujer (aunque puedan recibir ayuda de otras mujeres de la clase obrera a través de redes de solidaridad, esto es trabajo gratuito), aunque en el mundo obrero existan mujeres que puedan comprar fuerza de trabajo de otras para realizar 
el trabajo doméstico (Allemandi, 2017). Aquí me refiero a las que no lo pueden comprar - estas son la gran mayoría de las mujeres obreras - que asimismo, son las que otorgan más ganancia al capital patriarcal.

Entonces esta mujer tiene una extensísima jornada laboral por el salario que le pagan por su trabajo fuera de su hogar, por ese salario ella trabaja dentro y fuera. Esa larga jornada solo está separada por un viaje (que forma parte de su trabajo) y por el espacio (uno es el privado y otro es el público), pero estos son detalles: al capital patriarcal argentino de principios del siglo XX le era indiferente dónde estuviera utilizando su fuerza de trabajo, sino que solo le interesa esta per se. Asimismo, en general, no tiene relevancia la existencia de contratos en el capitalismo patriarcal, ¿o acaso a los empresarios los desvela hacer un contrato con los esclavos de los talleres textiles clandestinos de hoy en día? Ni siquiera les quita el sueño que tengan o no documentos de identidad. Por lo tanto, tomando como factor de análisis la fuerza de trabajo, la mujer está trabajando todo ese tiempo para el capital patriarcal tanto adentro como afuera de su casa y por un salario irrisorio: menos de la mitad de su jornada en la producción, menos que el salario masculino (ni siquiera los gastos de "subsistencia" - porque una gran parte los realiza gratuitamente- y el no-salario por su jornada de trabajo doméstico) es decir, casi un salario que no existe. De allí también puedo deducir la inferioridad de la mujer en esta sociedad, de la materialidad de su existencia.

Por lo tanto, las mujeres obreras se proletarizaron de una manera particular: condicionadas por su lugar en el sistema de sexo-género capitalista patriarcal. Las mujeres y los hombres se proletarizan en tanto tales (Artous, 1982). Su lugar en el sistema productivo está condicionado por la división sexual del trabajo. El hombre se proletariza a partir de su lugar de "proveedor" y la mujer desde su lugar de "reproductora", y esto genera diferencias en las experiencias de los hombres y de las mujeres. Como este trabajo reproductivo de la mujer no es reconocido en la sociedad, el trabajo de la mujer no existe como tal y es la razón de su invisibilidad; ${ }^{39}$ no es considerado trabajo socialmente válido, aunque sí lo sea. Esta invisibilidad se traslada al trabajo en los establecimientos fabriles de las mujeres y genera una diferencia abismal en cómo es considerado este trabajo según el sexo-género. Para las mujeres, el trabajo en estos establecimientos es entendido como complementario y de ayuda al trabajo del hombre, de manera que estas constituyen una mano de obra subcualificada, sometida más que los hombres al desempleo, con un salario que es considerado como apoyo o complemento del salario masculino y que es radicalmente menor que aquel. A su vez, se encuentran insertas en los empleos llamados "femeninos". Todos estos elementos generan una experiencia de clase particular, proveniente, como he expuesto, del lugar de las mujeres en la división sexual del trabajo que las ubica en la reproducción de la fuerza de trabajo para el capital patriarcal. Todo esto a nivel de la generación de plusvalor significa que la mujer tiene una jornada de trabajo más larga que la del hombre y recibe un salario mucho menor, lo que genera un plus en el plusvalor.

\section{Comentarios finales}

En este trabajo he tratado de mostrar cómo las mujeres históricamente, en la industria textil, y podría generalizarse a otros sectores laborales son víctimas de una explotación específica en el modo de producción capitalista patriarcal. Apoyándose en las diferencias sexuales, de género y generacionales, el capital patriarcal aumenta el plusvalor constantemente, porque es continua la inserción en el mercado laboral de las mujeres y cada vez es mayor la jornada laboral que la mujer le brinda al capital. 39 Para un análisis más amplio de esta temática ver Norando (2011a, 2013). 
Su fuerza de trabajo está cada vez más al servicio del capital patriarcal. Aquí he mostrado cómo la división sexual es uno de los mayores motores del capital, cómo las diferencias de género son utilizadas al extremo: se pagan salarios inferiores y se utiliza el trabajo no remunerado de las mujeres en sus casas. He mostrado también cómo la intersección clase-género-generación actúa en detrimento de las mujeres en beneficio del capital patriarcal, ya que eran empleadas preferenciales mujeres jóvenes y niñas (y he mencionado también argentinas) porque esto era más beneficioso, lo que se traduce en mayor plusvalor.

La jornada de las mujeres (tomada como jornada social de trabajo) es cada vez más larga, por lo tanto, el plusvalor es cada vez mayor. Esto hace que los salarios bajen cada vez más porque el trabajo doméstico sigue existiendo en la misma proporción en relación a las mujeres que entran al mercado laboral. Es una rueda que aumenta cada vez más la producción, la plusvalía y las ganancias. Es una rueda ascendente y desde el método materialista dialéctico es clara la contradicción que surge: de un trabajo profundamente precapitalista como el trabajo doméstico el capital es beneficiario y extrae una cantidad de plusvalor mayor que la que se puede obtener de un trabajo basado en el sexo que determina un trabajo exclusivamente capitalista. En essta tesis he buscado la unificación entre clase y género que va más allá de una intersección, la respuesta a una explotación específica y a cuál es su mecanismo de extracción del plusvalor.

La mujer de la clase trabajadora que no trabaja afuera de su casa y realiza las tareas domésticas lleva a cabo sus tareas más relajadamente y de manera más repartida en la semana, por ejemplo no trabaja el fin de semana o puede elegir no hacerlo, es decir trabaja menos horas, pero las hace igual, hace su jornada de trabajo con el salario del marido. Este salario no alcanza para pagar el trabajo doméstico, lo hace ella misma, por lo tanto, todas las mujeres de la clase trabajadora son las que realizan el trabajo doméstico. El trabajo doméstico tout court de las mujeres de la clase trabajadora es el que mantiene, reproduce y genera cada vez más plusvalor, no importa que no haya un contrato entre ellas y el capital. Las que trabajan fuera de su casa están en peores condiciones, tienen una jornada más larga de trabajo, y los capitalistas se apropian directamente de su trabajo doméstico. Las que no trabajan fuera de su casa tienen una jornada menos extensa y los capitalistas para los que trabajan sus maridos se apropian de sus trabajos por medio del salario que les pagan a sus compañeros.

Es decir, todos estos salarios encubren un no-salario de una jornada o una parte de una jornada que no se paga y que aumenta la plusvalía. Las trabajadoras textiles que han sido protagonistas de este estudio conforman una clase generizada en cuyo interior coexisten diferencias salariales extremas, pésimas condiciones de trabajo, evasión de las leyes obreras, etc. Todo esto forma parte de una experiencia obrera que hace a una explotación específica de la mujer trabajadora, que hay que continuar explorando, en diversos sectores laborales, más feminizados, menos feminizados, incorporar la dimensión de la etnia, etc. Hay muchos caminos por recorrer y muchas preguntas sin respuestas. 


\section{Q Referencias bibliográficas}

»Allemandi, C. (2017). Características y funcionamiento de un mercado de trabajo particular: el servicio doméstico en la ciudad de Buenos Aires (fines del siglo XIX y principios del XX). En Revista Brasileira de Historia, vol. 37.

"Andújar, A. (2015). Comunidad obrera, género y políticas asistenciales: Comodoro Rivadavia, 1922-1932. En Archivos, año IV, (7), pp. 59-78. Buenos Aires.

»------ (2016). Vivir con lo justo. Estudios de historia social del trabajo en perspectiva de género. Argentina, siglos XIX y XX. Rosario, Prohistoria.

»Artous, A. (1977). FALTA

»Artous, A. (1982). Los orígenes de la opresión de la mujer. Barcelona, Fontamara.

» Barandarian, L. (2017). La intervención estatal en el mundo del trabajo: la aplicación de la Ley de Descanso Dominical en el centro bonaerense (Tandil, 19171930). En Historia Caribe, vol. XII, núm. 31.

"Barrancos, D. (1990). Anarquismo, Educación y costumbres en la Argentina de principios de siglo. Buenos Aires, Contrapunto.

"Bellucci, M. (1992). Tensiones entre la reproducción social y la producción: estudio de caso de las mujeres gráficas de Buenos Aires (1890-1914). En II Jornadas de Historia de las Mujeres. Buenos Aires, Facultad de Ciencias Sociales, UBA.

» Bellucci, M. y Camusso, C. (1987-1989). Articulación de clase y género en las luchas de las mujeres anarquistas, Conicet.

»------ (1987). La huelga de inquilinos de 1907. El papel de las mujeres anarquistas. En Cuadernos CICSO, núm. 58.

"Benston, M. (1969). The Political Economy of Women's Liberation. En Monthly Review, vol. 21, núm. 40.

»Bilsky, E. (1985). La FORA y el movimiento obrero. Buenos Aires, Centro Editor de América Latina.

» Boris, E. y Klein, J. (2006). Organizing Home Care: Low-Waged Workers in the Welfare State. En Politics \& Society, vol. 34, Issue 1, pp. 81-108.

"Crenshaw, K. (1989). Demarginalizing the Intersection of Race and Sex: A Black Feminist Critique of Antidiscrimination Doctrine, Feminist Theory and Antiracist Politics. En University of Chicago Legal Forum, vol. 1989.

»Dalla Costa, M. R. (1972). Las mujeres y la subversión de la comunidad. Madrid, Siglo XXI.

»Delphy, C. (1977). Por un feminismo materialista. El enemigo principal y otros textos. Barcelona, LaSal.

»Departamento Nacional del Trabajo. Boletín

"D'Uva, F. y Palermo, S. (2015). Vida sindical y sociabilidades masculinas: los trabajadores ferroviarios en la Argentina de principios del siglo XX. En Archivos, año IV, núm. 7, setiembre.

"Eisenstein, Z. (1978). Hacia el desarrollo de una teoría del patriarcado capitalista y el feminism socialista. En Eisenstein Z. (comp.). Patriarcado capitalsta y feminismo socialista. Siglo XXI. 
"ENUT (2010). Encuesta Nacional de Uso del Tiempo, https://www.mimp.gob. pe/files/direcciones/dgignd/publicaciones/Brechas-de-genero-en-el-Uso-delTiempo.pdf

》Federici, S. (2010). Calibán y la bruja. Mujeres, cuerpo y acumulación originaria. Madrid, Traficantes de Sueños.

"Feijóo, M. (1990). Las trabajadoras porteñas a comienzo del siglo. En Armus, D. (comp.). Mundo urbano y cultura popular. Estudios de Historia Social Argentina. Buenos Aires, Sudamericana.

" Girar (1968). Girar, A. (1968). "The Time Budget of Married Women in Urban Centers, Population, $\mathrm{N}^{\circ} 48$.

" INDEC (2013). Encuesta sobre trabajo no remunerado y uso del tiempo, https:// www.indec.gob.ar/uploads/informesdeprensa/tnr_07_14.pdf

»Lobato, M. (1993). Mujeres obreras, protesta y acción gremial en la Argentina: los casos de la industria frigorífica y textil en Berisso. En Barrancos, D. Historia y Género. Buenos Aires, CEAL.

》------- (2001). La vida en las fábricas: trabajo, protesta y política en una comunidad obrera, Beriso (1904-1951). Buenos Aires, Prometeo.

"----- (2007a). Historia de las trabajadoras en la Argentina (1869-1960). Buenos Aires, Edhasa.

»------- (2007b). Historia de las instituciones laborales en Argentina: una asignatura pendiente. En Revista de Trabajo, año 3, núm. 4. Buenos Aires.

» Lobato, M. y Suriano, J. (Comps) (2014). La sociedad del trabajo. Las instituciones laborales en la Argentina, 1900-1955, Buenos Aires, Edhasa.

» Margarucci, I. (2015). Cocinando la revolución en la ciudad de La Paz, 1927-1946. En Archivos, año IV, (7), pp. 79-99. Buenos Aires.

» Mases, E.; Sancho, D. y Ramírez, N. (2015). Políticas estatales y trabajo infantil en la primera mitad del siglo XX. Los intentos de regulación y control en la Patagonia norte. Ponencia presentada en el III Congreso Nacional de Derecho Agrario Provincial. Neuquén.

» Norando V. (2011a). El Obrero Textil: dimensiones de una interpelación masculina hacia las trabajadoras del gremio entre 1933 y 1946. En Revista de Estudios Marítimos y Sociales, núm. 4, noviembre, Mar del Plata.

"----- (2013). Clase, Género y movimiento obrero en Buenos Aires. El caso de las obreras textiles entre 1890 y 1946: un avance teórico-metodológico. Anarres.

»----- (2016). Comunismo, Género y movimiento obrero: un estado de la cuestión. En Revista Izquierdas, núm. 30, octubre, pp.26-64. Santiago, Chile.

»------ (2018a). El Centenario y la participación de las trabajadoras textiles en la protesta obrera. Una perspectiva generizada del proceso huelguístico de 1910 en Buenos Aires. Establecimientos Gratry, Argentina. En Arenal, Revista de Historia de las Mujeresnúm 65,. Granada, .

»------ (2018b). Avanzando en una perspectiva teórica sobre las relaciones de género y clase en la historia del movimiento obrero. En La Ventana, núm. 48. Guadalajara, Universidad de Guadalajara.

"------ (2019a). Theoretical explorations on the specificity of working class women's exploitation. En La Ventana, núm. 49. México.

» -------- (2019b) “La ciudad arde este verano: Buenos Aires, enero de 1919. 
Roles sexuales y demandas por derechos de una clase obrera generizada", Revista Secuencia, núm 105, México.

»------ (2020). Rojas: Clase, Género y militancia comunista, 1936-1946. Buenos Aires, Imago Mundi.

"Norando y Scheinkman (2011). „“La Huelga de los Conventillos”, Nueva Pompeya, 1936. Un aporte a los estudios sobre género y clase“, A Contracorriente review. Vol. $9 \mathrm{~N}^{\circ}$, North Carolina, EE.UU.,

» Oddone (1975). Gremialismo proletario argentino, La Vanguardia, Ediciones Líbera, Buenos Aires

»Poy, L. (2015), Los orígenes de la clase obrera argentina, Buenos Aires, Imago MundiFALTA

"Queirolo, G. (2010). Las mujeres y los niños en el mercado de trabajo urbano (Buenos Aires, 1890-1940). En Recalde, H. Señoras, universitarias y mujeres (19102010). La cuestión femenina entre el centenario y el bicentenario de la Revolución de Mayo. Granada, Grupo Editor Universitario.

»---------- (2006) “Mujeres que trabajan: una revisión historiográfica del trabajo femenino en la ciudad de Buenos Aires" en Nuevo Topo. N. 3.

»Rodríguez Henríquez, (2015). “Economía feminista y economía del cuidado. Aportes conceptuales para el estudio de la desigualdad“, Nueva Sociedad, núm 256

» Rowbotham, (1977). Mundo de hombre conciencia de mujer, Tribuna feminista, Editorial Debate, Madrid

”Scheinkman, L. (2015a). “¿Dónde están los machos?” Sindicalización anarquista, masculina y femenina en la industria del dulce (Buenos Aires, 1920-1929). En Archivos, año IV, núm. 7, pp. 15-35. Buenos Aires.

»------- (2015b). Sujetos, instituciones y derechos en la implementación de la ley de accidentes del trabajo en la Ciudad de Buenos Aires (1915-1922). En Estudios Sociales, núm. 49.

» Scheinkman, L. (2017). “Dulces consumidores. La construcción publiscitaria del consumo femenino e infantil de golosinas en las primeras décadas del siglo XX en la Argentina, Meridional“, Revista Chilena de Estudios Latinoamericanos, núm 9.

»Trebisacce, C. y Mangiantini, M. (2015). Feminismo, diversidad sexual y relaciones sexo-afectivas disidentes. Apuestas y tensiones en el PST, 1971-1975. En Archivos, año IV, (7), pp. 101-120. Buenos Aires. 